\title{
LA EXPRESIÓN DEL NÚMERO NOMINAL EN BRIBRI
}

\author{
Haakon S. Krohn
}

\section{(c) $(7)(9)$}

Esta obra está bajo una licencia Creative Commons 



\title{
LA EXPRESIÓN DEL NÚMERO NOMINAL EN BRIBRI
}

\author{
THE EXPRESSION OF NOMINAL NUMBERS IN THE BRIBRI \\ LANGUAGE
}

\author{
Haakon S. Krohn
}

\begin{abstract}
RESUMEN
Este artículo aborda la amplia variedad de estrategias empleadas en el bribri para expresar el número de referentes nominales. Estas incluyen tanto el uso de cuantificadores como las diferentes maneras de codificar morfológicamente la categoría gramatical de número, la cual distingue entre singular y plural. Además, el artículo analiza los factores que permiten la omisión de la marcación de plural en ciertas palabras que aluden a un referente de este número.

Palabras clave: bribri, número nominal, número gramatical, plural, morfología.
\end{abstract}

\begin{abstract}
This paper deals with the wide range of strategies employed in Bribri to express the number of nominal referents. These strategies include both the use of quantifiers and the different ways to codify the grammatical category of number, which distinguishes between singular and plural. The paper also analyzes the factors that allow the speaker to leave out the plural marking in certain words with a plural referent.

Key words: Bribri, nominal number, grammatical number, plural, morphology.
\end{abstract}

\section{Introducción}

La expresión del número nominal ${ }^{1}$ comprende cualquier indicación lingüística de la cantidad de un referente nominal. Este número puede manifestarse como una categoría flexiva, fenómeno conocido como número gramatical, o bien ser marcado por medio de cuantificadores numerales o indefinidos, los cuales constituyen indicaciones más específicas de la cantidad.

Este artículo se centra en la expresión del número nominal en bribri, un idioma chibchense hablado en Costa Rica y Panamá. ${ }^{2}$ El trabajo se fundamenta en las descripciones gramaticales encontradas en Constenla, Elizondo y Pereira (1998), y Jara y García (2009; 2013),

M.L. Haakon Stensrud Krohn. Universidad de Costa Rica. Profesor. Escuela de Filología, Lingüística y Literatura. Costa Rica.

Correo electrónico: hkrohn@gmail.com

Recepción: 25- 05- 2015

Aceptación: 15- 07- 2015 
así como en una serie de sesiones de elicitación con Alí García Segura, hablante nativo de la variedad de Coroma, uno de los tres dialectos geográficos principales de este idioma. ${ }^{3}$

El presente texto está estructurado en tres partes: Primero, versa sobre el concepto de número nominal y otras nociones relacionadas. Seguidamente, presenta las diferentes estrategias exhibidas en el bribri para expresar el número de referentes nominales. Por último, analiza hasta qué grado las distintas marcaciones del plural son obligatorias en dicha lengua y en qué contextos se pueden omitir.

\section{Generalidades sobre la expresión del número nominal}

En una lengua, la expresión del número nominal puede darse en cualquier parte de la cláusula, tanto dentro como fuera del sintagma nominal. Además, en las lenguas del mundo se ha identificado una gran variedad de estrategias para expresarlo; puede indicarse, por ejemplo, mediante afijos flexivos, modificaciones de raíces, palabras especiales de cuantificación o estrategias léxicas como la supleción (Kibort y Corbett, 2008).

En el caso del español, la codificación gramatical del número nominal puede representar uno de dos valores: singular o plural. El ejemplo (1a) ilustra cómo el número singular del referente del sustantivo edificio es expresado mediante el artículo singular el y un morfema cero tanto en el propio sustantivo como en las demás palabras de la cláusula. En cambio, en (1b), el sustantivo alude a un referente plural, lo cual se marca morfológicamente en el sustantivo, en las otras palabras del sintagma nominal (el artículo y el adjetivo), en el verbo y en el adjetivo que constituye el atributo, como consecuencia de la concordancia gramatical obligatoria. A pesar de que este fenómeno resulte en una indicación múltiple del número que se puede considerar redundante, la gramática española no permite la omisión de ninguna de estas marcaciones.

a. El edificio nuevo era alto.

b. Los edificios nuevos eran altos.

Asimismo, el número nominal puede expresarse de manera más específica por medio de un cuantificador indefinido, o de modo exacto con un cuantificador numeral. En este idioma, como se observa en el ejemplo (2), el uso de un cuantificador que implica plural no causa la omisión de la marcación flexiva de dicho número en ninguna de las otras palabras de la cláusula.

\section{\{Cuatro/Cien/Muchos/Algunos\} edificios nuevos eran altos.}

En las lenguas que codifican el número nominal como una categoría gramatical, caso del español, bribri y prácticamente todas las lenguas del mundo (Corbett, 2000, p. 50), siempre existe por lo menos la distinción entre singular y plural. Adicionalmente, muchas lenguas poseen divisiones más finas del plural, con categorías como dual, trial o paucal ("pocos"). Con respecto a esto, el universal 34 de Greenberg (1963, p. 94) afirma lo siguiente: "No language has a trial number unless it has a dual. No language has a dual unless it has a plural." Dicho universal se puede formalizar por medio de la jerarquía en (3), la cual expresa que una lengua que presenta una marcación gramatical de alguno de estos números, también posee marcación gramatical para todos los números que se encuentran a la izquierda en la jerarquía.

$$
\text { singular }>\text { plural }>\text { dual }>\text { trial }
$$


De estos, el singular tiende a ser el número morfológicamente menos marcado, como señala el universal 35 del mismo autor (Greenberg, 1963, p. 94):

\footnotetext{
There is no language in which the plural does not have some nonzero allomorphs, whereas there are languages in which the singular is expressed only by zero. The dual and the trial are almost never expressed only by zero.
}

Ahora bien, en la mayoría de las lenguas, la diferenciación del número nominal se suele manifestar solo con ciertos tipos de referentes. Por ejemplo, en español, persona y casa pueden considerarse sustantivos altamente pluralizables, mientras que algunos de los nombres que codifican conceptos abstractos, como salud y sed, difícilmente aparecen en plural. A nivel interlingüístico, de acuerdo con Corbett (2000, p. 56, basado en Smith-Stark, 1974), se observa un patrón que se puede describir en términos de la jerarquía presentada en (4). Si un referente de alguno de los tipos señalados se puede pluralizar gramaticalmente en determinada lengua, todos los tipos de referentes que se encuentran a su izquierda en la jerarquía también suelen permitir tal marcación gramatical.

(4) hablante $>$ destinatario $>3^{\mathrm{a}}$ persona $>$ pariente $>$ humano $>$ animado $>$ inanimado

Se puede apreciar que la parte derecha de la jerarquía ("humano > animado > inanimado") gradúa la animicidad del referente; una entidad inanimada no se marca como plural si una animada no se marca, y un referente animado no humano (típicamente un animal) no permite la marcación plural si esta no se da con una palabra que denota a un humano. Además, como se ilustró con los sustantivos españoles salud y sed, una lengua puede presentar distinciones más específicas; en este caso con la ausencia de marcación plural en ciertos sustantivos cuyos referentes son abstractos, los cuales constituirían un subgrupo de los inanimados. La base cognitiva de esta parte de la jerarquía es, evidentemente, un punto de vista antropocéntrico.

En cambio, la parte izquierda es, más bien, una jerarquía de persona, según la cual un ser humano que se encuentra más cerca del hablante o de la situación comunicativa, en sentido figurado, tiene mayor posibilidad de recibir marcación de número, ya que tal distinción se hace más relevante. La jerarquía (4) en su totalidad, como observa Langacker (1991, p. 306), corresponde a la noción de empatía por parte del hablante. Por lo tanto, será referido como la Jerarquía de Empatía a lo largo de este artículo.

\section{Estrategias para expresar el número nominal en bribri}

En esta sección se examinarán todas las estrategias empleadas en bribri para expresar el número de un referente nominal. Será evidente que este idioma distingue gramaticalmente entre singular y plural, con el plural como el número morfológicamente marcado.

Las dos primeras estrategias que se van a tratar son las que incluyen el uso de un cuantificador:

1. Cuantificadores numerales

2. Cuantificadores indefinidos

Seguidamente, se presentarán las estrategias gramaticales. Tres de estas se dan en el elemento nominal (un sustantivo o un sustantivo personal), ${ }^{4}$ es decir, en la misma palabra que 
representa al referente; en ninguna circunstancia se emplea más de una de estas tres estrategias a la vez, ya que cada una corresponde a un grupo específico de palabras:

3. Sufijo $-p a^{5}$ en el sustantivo

4. Reduplicación de la raíz del sustantivo

5. Raíces propias de plural de sustantivos personales

Por último, cinco estrategias se presentan en otras partes de la cláusula; la primera de estas, la forma plural de un adjetivo, puede aparecer en un sintagma nominal o en el atributo de la cláusula, mientras que las otras cuatro siempre se ubican en el predicado:

6. Formas plurales de adjetivos

7. Formas plurales de posicionales

8. Formas plurales de direccionales

9. Sufijo - dak -rak en el verbo o en la posposición

10. Sufijo -yar -lar en el verbo

\subsection{Cuantificadores numerales}

Los cuantificadores numerales constituyen la única estrategia para expresar el número exacto de un referente en bribri. Este idioma posee raíces numerales del uno al diez, los cuales se pueden combinar para aludir a cantidades mayores.

El bribri es una lengua de clasificadores numerales, por lo que cada vez que se utiliza un numeral (con la excepción de 'diez' y, en la mayoría de los casos, 'nueve'), aparece un morfema adicional, denominado clasificador, el cual alude a una o varias propiedades de la entidad cuantificada. En esta lengua, el clasificador se agrega al numeral en forma de sufijo. Krohn (2014) identifica once morfemas clasificadores diferentes (de los cuales dos son homófonos) en el ámbito nominal en la variedad dialectal de Coroma. ${ }^{6}$ Estos pueden dividirse en dos grupos principales según sus rasgos semánticos: los que codifican una o varias propiedades de instancias individuales del referente se consideran sortales, y los que aluden a las características de conjuntos del referente son denominados mensurativos.

Los numerales junto con los distintos clasificadores se presentan en las siguientes tablas (adaptadas de Krohn, 2014, p. 216); la tabla 1 incluye los sortales y la tabla 2, los mensurativos. Nótese que los morfemas que expresan las categorías de PLANTA EN PIE y UNIDAD DE PESO son homófonos, pero con significados claramente diferentes. Las palabras en cursiva no llevan el sufijo correspondiente, lo cual se debe a uno de dos factores: o es una forma supletiva tomada de la serie humana, que es el caso en todos los numerales en itálica menores de 'ocho'; o no lleva ningún clasificador (o un sufijo cero), lo cual ocurre con las palabras en itálica con valores de 'nueve' o 'diez'. El hecho de que algunas casillas del cuadro están vacías se debe a que esas combinaciones de numeral+clasificador son consideradas agramaticales; lo mismo sucede con la raíz 'diez' con cualquiera de los clasificadores mensurativos. 
Tabla 1. Numerales bribris del uno al diez con los diferentes clasificadores sortales

\begin{tabular}{|c|c|c|c|c|c|}
\hline & Humano & Redondo & Aalargado & $\begin{array}{l}\text { Plano/ } \\
\text { abstracto }\end{array}$ & Planta en pie \\
\hline & $-l$ & $-k$ & -töm & $-t$ & $-l k a$ \\
\hline 1 & èköl & èköl & ètöm & èt & élka \\
\hline 2 & böl & bö̀k & bö̀töm & bö̀t & bólka \\
\hline 3 & mañál & mañál & mañàtöm & mañàt & mañálka \\
\hline 4 & tchếl & tchél & tchë̀töm & tchël & tchëlka \\
\hline 5 & skếl & skếl & skềtöm & skếl & skếllka \\
\hline 6 & tèröl & tèröl & tèktöm & tèröl & \\
\hline 7 & kúl & kúl & kùktöm & kúl & \\
\hline 8 & pàköl & pàköl & pàktöm & pàköl & \\
\hline 9 & sũlı̀tu & sũlì̀tu & sũlìtöm & sũlì̀tu & \\
\hline 10 & dabòm & dabòm & dabòm & dabòm & \\
\hline
\end{tabular}

Tabla 2. Numerales bribris del uno al nueve con los diferentes clasificadores mensurativos

\begin{tabular}{|c|c|c|c|c|c|c|}
\hline & $\begin{array}{l}\text { Racimo de } \\
\text { banano }\end{array}$ & $\begin{array}{l}\text { Racimo de } \\
\text { pejibaye }\end{array}$ & Puño & $\begin{array}{l}\text { Paquete/ } \\
\text { bulto }\end{array}$ & $\begin{array}{l}\text { Especie/ } \\
\text { clase }\end{array}$ & $\begin{array}{l}\text { Unidad de } \\
\text { peso }\end{array}$ \\
\hline & $-y u w a k$ & $-t s \tilde{o} k$ & $-y \ddot{o k}$ & $-k u a$ & -ltë & $-l k a$ \\
\hline 1 & ètyuwak & étsõk & èyök & étkua & éltë & élka \\
\hline 2 & bötyuwak & bö̀tsõk & böyök & bö̀tkua & bốltë & bölka \\
\hline 3 & mañátyuwak & mañàtsõk & mañàyök & mañàtkua & mañáltë & mañálka \\
\hline 4 & tchëlyuwak & & tchëyök & tchëtkua & tchëltë & tchëlka \\
\hline 5 & skếlyuwak & & skếyök & skềtkwua & skếltë & skếlka \\
\hline 6 & & & tèryök & & & \\
\hline 7 & & & kúlyök & & & \\
\hline 8 & & & pàryök & & & \\
\hline 9 & & & sũlì̀tuyök & & & \\
\hline
\end{tabular}

En (5) se ilustra la función de los clasificadores sortales, y la de los mensurativos es ejemplificada en (6). Como se puede apreciar, los clasificadores permiten la enumeración de cualquier referente, inclusive los que en español se codifican por medio de sustantivos típicamente incontables, como en los ejemplos (5b) y (6b). Cabe señalar que el numeral siempre cuantifica el concepto codificado por el clasificador, no directamente al sustantivo; por esta razón, (6a) se traduce como 'cuatro racimos de banano', y no 'un racimo de cuatro bananos'.
a.
àshali bök
naranja dos-CLRED
'dos naranjas'
b. di’ mañàtöm
agua tres-CLALA
'tres ríos' 


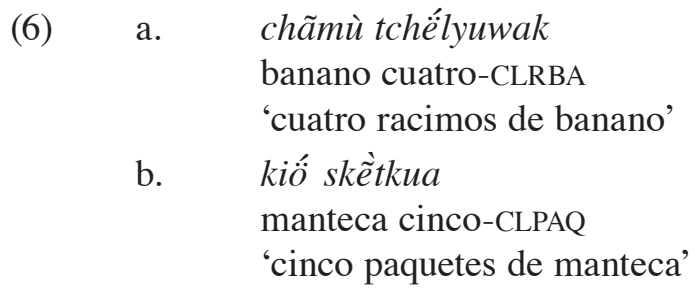

También se puede utilizar el numeral 'uno' reduplicado para indicar que el referente es plural, caso en el que se traduciría al español como 'algunos'; esto se ejemplifica en (7).

$$
\begin{aligned}
& \text { buà ètöm ètöm } \\
& \text { iguana uno-CLALA uno-CLALA } \\
& \text { 'algunas iguanas' }
\end{aligned}
$$

\subsection{Cuantificadores indefinidos}

El bribri también posee varios cuantificadores indefinidos, los cuales proporcionan una cuantificación menos específica que los numerales, pero más específica que la categoría gramatical de número. Los cuantificadores indefinidos más comunes, que todos implican que su referente es plural, se presentan junto con su traducción aproximada en la tabla 3.

Tabla 3. Cuantificadores indefinidos bribris que implican plural

\begin{tabular}{|l|l|}
\hline wökĩla & 'pocos' \\
\hline wếlè & 'algunos' \\
\hline tsée & 'varios' \\
\hline tấĩ & 'muchos' \\
\hline ulìtãne & 'todos' \\
\hline kốs & 'todos' \\
\hline
\end{tabular}

De este modo, un cuantificador indefinido constituye la única expresión del número plural de tsawì 'armadillo' en las dos oraciones en (8).

(8) a. Ye’ tö tsawì sãwé tsée.

1SG ERG armadillo ver-PRC muchos

'Yo vi muchos armadillos.'

b. Ye' tö tsawì ulìtãne sãwé.

1SG ERG armadillo todos ver-PRC

'Yo vi todos los armadillos.'

\subsection{Sufijo - $p a$ en el sustantivo}

El sufijo - $p a$ es un morfema flexivo que se le puede agregar a un sustantivo para indicar que su referente es plural, como se aprecia en (9).
a. aláköl 'mujer'
alákölpa 'mujeres'
b. awá 'médico, suquia'
awápa 'médicos, suquias' 
Su uso es restringido a los sustantivos comunes que aluden a un ser humano, por lo que generalmente no se utiliza con sustantivos que denotan partes del cuerpo, animales o cualquier otro objeto o concepto, restricción en la que se manifiesta la Jerarquía de Empatía. En (10) se consignan algunos de los sustantivos humanos.

(10) Término general:

$p \dddot{e}$ ' 'persona, gente'

Términos relacionados con género/edad:

wëm 'hombre', aláköl 'mujer', alà 'niño', bùsi 'muchacha', kabè 'muchacho'

Términos de parentesco:

mì 'madre', yë 'padre', wĩ̀ ke 'abuela, anciana', yàmi 'pariente, amigo'

Cargos:

awá 'médico indígena', sĩ̃o'tãmi 'mujer encargada de las piedras del médico', yéria 'cazador'

Seres sobrenaturales:

dichèkala 'alma de los huesos', diốköl 'alma de los ojos', alàr 'duende', abèbulu 'diablo', áknama 'diablo'

Asimismo, el sustantivo personal de tercera persona, ie', también admite el sufijo cuando su referente es plural; esto se ilustra en (11).

(11) ie' 'él, ella' ie’pa 'ellos, ellas'

Algunos sustantivos sufren cambios en la raíz al agregarse este sufijo. Por ejemplo, wém 'hombre' pierde la consonante nasal, como se muestra en (12).

$$
\text { wëm 'hombre' wёpa 'hombres' }
$$

Otros sustantivos pasan por un cambio de tono al agregarse el sufijo - $p a$. De acuerdo con Constenla, Elizondo y Pereira (1998, p. 7), “[1]os sustantivos terminados en vocal con tono alto cambian este tono por el descendente cuando se les añade la flexión de plural”. Además, según los mismos autores, "[1] os sustantivos terminados en vocal con tono bajo precedida a su vez por vocal con tono alto, cambian, en el habla del este de Talamanca, el tono bajo por tono descendente al añadírseles el pluralizador". En (13) se presentan ejemplos de los dos casos, tomados de Constenla, Elizondo y Pereira (ibid.). ${ }^{7}$

$$
\begin{array}{llll}
\text { naũ } & \text { 'tío materno' } & \text { naûpa } & \text { 'tíos maternos' } \\
\text { yàmi } & \text { 'pariente, amigo' } & \text { yàmípa } & \text { 'parientes, amigos' }
\end{array}
$$

No obstante, si el hablante concibe un animal como antropomorfizado, el sustantivo que lo denota también puede recibir el sufijo - pa. Esto sucede sobre todo en la literatura oral tradicional. En tales casos se nota claramente la relación entre la marcación morfológica de plural y la Jerarquía de Empatía: con el morfema - pa, el referente es elevado a una posición empáticamente más cercana al hablante, la de "humano", en la cual se hace relevante esta distinción de número. De acuerdo con el informante, ocurre con frecuencia que los bribris más jóvenes generalizan el uso de - $p a$ a todos los animales en cualquier contexto, hábito corregido por los mayores. 
Por último, cabe señalar una característica particular del uso de este sufijo. En la visión del mundo bribri, cada persona está formada por cuatro seres: Wöbla Wíköl (los ojos), Yàblo (el hígado), Dachékla (los huesos) y Se’ Wíköl (el alma). En consecuencia, es común que lo que en la cultura occidental se considera un solo ser humano se exprese en bribri mediante un sustantivo con el sufijo - $p a$, lo cual suele llevar una connotación de respeto.

\subsection{Reduplicación de la raíz del sustantivo}

El único sustantivo con referente humano que no admite el morfema -pa es alà 'niño'. Este, en cambio, es marcado como plural por medio de una reduplicación de la raíz, como es ilustrado en (14).

$$
\text { alà 'niño' }
$$

alàralar

'niños'

En las variedades bribris analizadas por Constenla, Elizondo y Pereira (1998), no se da la reduplicación sino una forma ala'r que según dichos autores no es de plural sino que es "de carácter colectivo, que literalmente significar [sic] "prole, conjunto de niños" (p. 8). No obstante, en el dialecto de Coroma, alàralar se comporta semánticamente igual que los sustantivos que llevan el sufijo - pa.

\subsection{Raíces propias de plural de sustantivos personales}

En la serie de sustantivos personales, el bribri distingue entre singular y plural en las tres personas. Además, discierne entre el inclusivo y el exclusivo de la primera persona plural. Como ya se ha visto, el plural de la tercera persona se forma mediante el sufijo - pa: ie'pa. En contraste, en la primera y la segunda persona, las formas plurales constituyen raíces diferentes de las singulares. Un cambio en la raíz también establece la distinción entre la primera persona del plural inclusiva y exclusiva. Todos los sustantivos personales del bribri se aprecian en la tabla 4.

Tabla 4. Sustantivos personales en bribri

\begin{tabular}{|l|c|c|c|}
\hline & Singular & Plural & \\
\hline $\mathbf{1}^{\text {a }}$ persona & ye' & se' & \multirow{2}{*}{ (inclusiva) } \\
& & sa' & (exclusiva) \\
\hline $\mathbf{2}^{\text {a }}$ persona & be' & a' & \\
\hline $\mathbf{3}^{\text {a }}$ persona & ie' & ie'pa & \\
\hline
\end{tabular}

Los sustantivos personales se emplean exclusivamente con referentes humanos, es decir, los mismos que son representados por sustantivos que reciben la marcación - pa en plural, lo cual explicaría por qué todos los sustantivos personales distinguen entre número singular y plural. El hecho de que la primera y la segunda persona presentan un tipo de marcación diferente de la tercera persona, también podría explicarse por medio de la Jerarquía de Empatía, ya que las dos primeras ocupan posiciones superiores. Además, según señala Corbett (2000), los nominales que se ubican en las posiciones más altas de la jerarquía tienden a utilizarse más como asociativos en vez de como plurales verdaderos. Efectivamente, $s e^{\prime}$ (primera persona plural inclusiva) y $s a^{\prime}$ (primera persona plural exclusiva) serían plurales verdaderos solamente si todos los referentes (es decir, todos los individuos a los que alude la palabra) la pronuncian 
al mismo tiempo. De ser pronunciada únicamente por una persona, funcionaría como un asociativo, ya que su significado es 'yo más otras personas asociadas conmigo' y no ‘yo más yo más yo, etc.'. De igual manera, $a$ ' (segunda persona plural) es un plural verdadero solamente cuando el emisor les habla a todos los referentes al mismo tiempo.

\subsection{Formas plurales de adjetivos}

Ciertos adjetivos bribris presentan una forma especial para el plural. Esta consiste en una reduplicación de la raíz de la forma singular (o de una raíz diferente en el caso de bërie 'grande'). Jara y García (2013, p. 131) presentan cuatro adjetivos con esta particularidad, los cuales se exponen en la tabla 5.

Tabla 5. Adjetivos bribris que presentan una forma plural

\begin{tabular}{|l|l|l|l|}
\hline \multicolumn{2}{|l|}{ Singular } & \multicolumn{2}{l|}{ Plural } \\
\hline bua' & 'bueno' & bua'bua' & 'buenos' \\
\hline buáala & 'bonito' & buàmbuáala & 'bonitos' \\
\hline bërie & 'grande' & bulùbulù & 'grandes' \\
\hline tsìr & 'pequeño' & tsìrtsir & 'pequeños' \\
\hline
\end{tabular}

A diferencia de las estrategias gramaticales señaladas anteriormente en el presente artículo, esta marcación de plural se da con cualquier referente nominal, sea humano, animal o inanimado. Por tanto, aunque dù 'pájaro' y ák 'piedra' carecen del sufijo -pa en (15) (por no ser humanos), la pluralidad de su referente sí se manifiesta en el adjetivo, que adquiere su forma plural.
a. dù bulùbulù
pájaro grande-PL
'pájaros grandes'
b. ák buàmbuáala
piedra bonita-PL
'piedras bonitas'

De acuerdo con Constenla, Elizondo y Pereira (1998, p. 60), también otros adjetivos se pueden reduplicar; un ejemplo ofrecido por dichos autores es sarûrû 'blanco', que puede adquirir la forma sarûrû sarûrû para expresar plural. Sin embargo, la reduplicación de ciertos adjetivos (típicamente los que denotan colores) no indica plural, sino un grado atenuado (Constenla, Elizondo y Pereira, 1998, p. 60).

Los adjetivos pueden aparecer dentro del sintagma nominal, como se apreció en (15), o en el atributo, como en (16), donde solamente la forma del adjetivo especifica el número gramatical de $\grave{u}$ 'casa'.
a. $\quad$ U dör bè̈rie.
casa COP grande
'La casa es grande.'
b. Ù dör bulùbulù .
casa COP grande-PL
'Las casas son grandes.' 
La marcación de plural por medio de un adjetivo es a menudo obviada, de ahí que la casa en (17) pueda ser tanto singular como plural, dependiendo del contexto.

\author{
Ù dör kốjkè̀. \\ casa COP alto \\ 'La casa es alta. / Las casas son altas.'
}

\title{
3.7 Formas plurales de posicionales
}

El bribri posee una categoría de palabras que aparecen en el predicado para indicar la posición o postura de un referente nominal. En este artículo se tratan bajo el término de posicionales. ${ }^{8}$ Su semántica es explicada con mayor detalle en Constenla, Elizondo y Pereira (1998, pp. 67-68), y Jara y García (2013, pp. 102-107).

Los posicionales en bribri aparecen en un tipo de cláusulas que corresponde a lo que en muchas lenguas se codifica por medio de dos estructuras diferentes, a saber, las construcciones locativas básicas (que se utilizan para expresar dónde algo se encuentra; en español suelen incluir el verbo estar) y las construcciones existenciales/presentativas (verbo haber en español) (cf. Grinevald, 2006, p. 32). En el aspecto imperfectivo afirmativo, estas cláusulas se forman con el verbo estativo tso', el cual se elide cuando se incluye un posicional en el predicado. En cambio, no se da la elisión del verbo en el aspecto imperfectivo negativo (donde el verbo adquiere la forma $k \tilde{u}$ ) ni en el perfectivo (en el que el verbo es bák).

Cada posicional (con la excepción de uno que no se incluye aquí) posee una forma singular y una plural, con referencia al número de la entidad denotada por el único argumento verbal o el argumento ergativo de la cláusula. Ambas formas de los posicionales, junto con su significado aproximado (según Jara y García, 2013, p. 103), se presentan en la tabla 6.

Tabla 6. Posicionales en bribri

\begin{tabular}{|l|l|l|}
\hline Singular & Plural & Significado aproximado \\
\hline dur & iè̀tẽn & de pie, parado, erguido \\
\hline tchër & tulur & sentado, posado, puesto \\
\hline tẽr & tulur & metido, enterrado, clavado \\
\hline tër & tchë̀tẽn & tirado, tendido, echado \\
\hline ar & tchè̀nik & colgado, suspendido, flotando \\
\hline bàtsul & bàtsulur & apoyado, pegado verticalmente \\
\hline mer & dapárke & puesto/acostado en algo elevado \\
\hline
\end{tabular}

El ejemplo (18) muestra que el posicional aparece en su forma plural cuando el sustantivo wè̀m 'hombre' alude a un referente plural en (18b). En este caso, el número gramatical se marca tanto en el sustantivo como en el posicional, puesto que se trata de un referente humano.

(18) a. Wëm tchër kula'kĩ. hombre sentado banca en

'El hombre está sentado en la banca.' 


\section{b. Wépa tulur kula' kĩ.}

hombre-PL sentado.PL banca en

'Los hombres están sentados en la banca.'

Similarmente, en (19), el número gramatical del argumento verbal, chìchi 'perro', es codificado por medio del posicional. A diferencia del ejemplo (18), el referente de dicho sustantivo no es humano, por lo que el posicional constituye el único marcador de su número.
a.
Chìchi tërî́s kĩ.
perro echado suelo en
'El perro está echado en el suelo.'
b. Chìchi tchètẽ̃n î́s kĩ. perro echado.PL suelo en
'Los perros están echados en el suelo.'

\subsection{Formas plurales de direccionales}

El bribri también dispone de un conjunto de sufijos direccionales, que se agregan a ciertos verbos y posicionales. Como se señala en Constenla, Elizondo y Pereira (1998, pp. 27-28 y p. 130), tres de los direccionales presentan formas distintas según el número del absolutivo; estos se exponen en la tabla 7. Los significados aproximados muestran que también pueden aportar información más allá del dominio espacial.

Tabla 7. Direccionales bribris que varían según el número del absolutivo

\begin{tabular}{|l|l|l|}
\hline Singular & Plural & Significado aproximado \\
\hline -wa & -alor & $\begin{array}{l}\text { movimiento descendente / afectación } \\
\text { total del absolutivo }\end{array}$ \\
\hline -wã & -ulur & $\begin{array}{l}\text { movimiento de penetración / valor } \\
\text { aspectual puntual }\end{array}$ \\
\hline -stsã & -ulur & movimiento de separación \\
\hline
\end{tabular}

En (20), el sufijo -wãa, que en este caso ha perdido su sentido original de movimiento de penetración, constituye el único indicador del número del absolutivo.
a. Sĩni' kapë'wã.
chancho.de.monte dormirse-PRM-DIRPEN.SG
'El chancho de monte se durmió.'
b. Sĩni' kapë'ulur.
chancho.de.monte dormirse-PRM-DIRPEN.PL
'Los chanchos de monte se durmieron.'

Similarmente, los ejemplos en (21) evidencian la variación del direccional -sts ã.
a. Ie' tö së yë'stsã.
3 ERG horcón sacar-PRM-DIRSEP.SG
'Él/ella sacó el horcón.'
b. Ie' tö së yë'ulur.
3 ERG horcón sacar-PRM-DIRSEP.PL
'Él/ella sacó los horcones.' 


\subsection{Sufijo $-d a k \sim-r a k$ en el verbo o en la posposición}

De acuerdo con Constenla, Elizondo y Pereira (1998, p. 53), el sustantivo personal ie' (de tercera persona) tiende a debilitarse y convertirse en un proclítico $i$. En tales ocasiones, el plural no se marca con el habitual sufijo - $p a$ en el nominal (lo cual daría *ipa), sino por medio de un sufijo -dak $\sim$-rak (el último de estos alomorfos aparece después de vocal; el primero, en los demás casos) que se agrega al verbo si el sustantivo personal debilitado funciona como argumento verbal, o a la posposición en el caso de que el sustantivo personal sea el complemento de esta. El fenómeno ocurre tanto con verbos intransitivos como transitivos; ${ }^{9}$ en las cláusulas transitivas, puede darse tanto con el actante ergativo como con el absolutivo. En el caso de una forma verbal compuesta, el sufijo se une al auxiliar.

En (22) se presentan ejemplos que incluyen la forma no debilitada de $i e$ ' junto con la construcción equivalente con el proclítico $i$ y el sufijo - $d a k \sim-r a k$ en el verbo: en (22a) se da con una posposición, en (22b) con un verbo intransitivo, en (22c) con el auxiliar de un verbo intransitivo, en (22d) con el ergativo de una cláusula transitiva y en (22e) con el absolutivo de una cláusula transitiva.

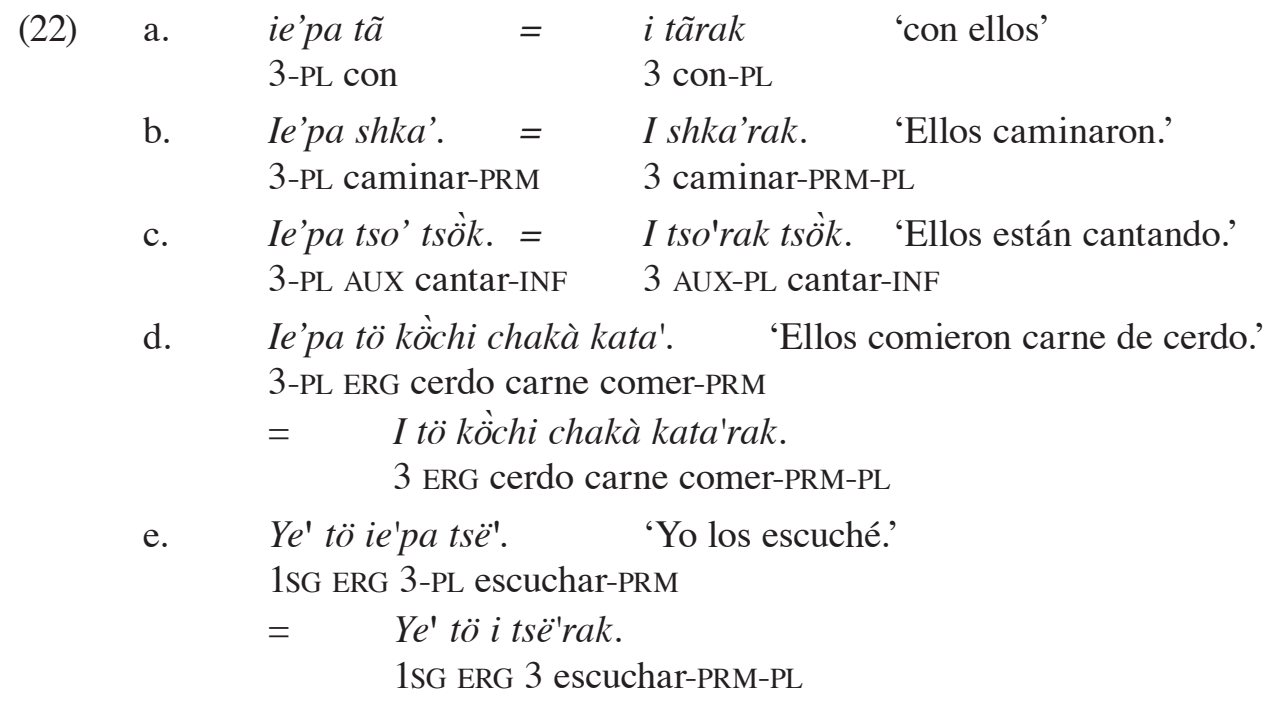

\subsection{Sufijo -yar - -lar en el verbo}

En la gran mayoría de los casos, los verbos bribris no concuerdan en número con sus argumentos (a pesar de cuando reciben el sufijo - dak $\sim$-rak tratado arriba). Sin embargo, ciertos verbos intransitivos adquieren un sufijo en el aspecto perfectivo ${ }^{10}$ cuando el argumento verbal es plural. El más común de estos verbos es mík 'irse', cuyas formas perfectivas se consignan en la tabla 8; la marca del plural es el sufijo -yar.

Tabla 8. Las formas del verbo mík 'irse' que distinguen entre singular y plural

\begin{tabular}{|l|l|l|}
\hline & Singular & Plural \\
\hline Perfectivo reciente & mía & míyar \\
\hline Perfectivo remoto & mìne & mìneyar \\
\hline
\end{tabular}


De esta manera, el agente talók 'cocodrilo' es plural en (23b), siendo la presencia del sufijo -yar la única indicación del número.
a. Talók mine di' ã . cocodrilo irse-PRM agua a
'El cocodrilo se fue al río.'
b. Talók mineyar di' a .
cocodrilo irse-PRM-PL agua a
'Los cocodrilos se fueron al río.'

El mismo morfema aparece en el aspecto perfectivo remoto del verbo ponuk 'irse/ dispersarse': póneyar. Con este verbo, el sufijo no se utiliza en perfectivo reciente. Cabe agregar que -yar no aparece en ninguno de los dos verbos mencionados cuando el argumento es un sustantivo personal de primera y segunda persona del plural, lo cual subraya la función de estas palabras como asociativos más que plurales propiamente dichos.

Adicionalmente, la raíz verbal yá- (que porta el significado de 'llegar' o 'ser traído') puede llevar el sufijo -lar, que parece ser un alomorfo de -yar, para indicar el plural del argumento absolutivo en una construcción sintácticamente intransitiva. Esto se observa en el ejemplo (24), donde el único argumento verbal es namà 'pez' (el agente semántico, ie' 'él/ella', no es argumento verbal, lo cual es señalado por la posposición $w \tilde{a})$, por lo que la forma yálar indica que se trata de más de un pez.

$$
\begin{aligned}
& \text { Ie' wã namà yálar } \\
& 3 \text { AG pez llegar-PRC-PL } \\
& \text { 'Él/ella trajo peces.' }
\end{aligned}
$$

Además de los verbos mencionados, el informante afirmó que el morfema -yar se emplea con una mayor cantidad de verbos en otros dialectos bribris. Futuras indagaciones podrán dar cuenta de estos usos y, posiblemente, se podrá encontrar un patrón semántico compartido por los verbos que aceptan el sufijo, dado que todos los que fueron hallados en la variedad de Coroma son de movimiento.

\section{Omisión de la marcación de plural}

A diferencia de por ejemplo el español, el bribri no presenta concordancia obligatoria en la flexión de número. Por lo tanto, no necesariamente todas las palabras pluralizables (es decir, las que pueden llevar tal marcación morfológica) aparecen en su forma plural aunque denotan a un referente de dicho número. En esta sección se analizarán los factores que permiten la omisión de la marcación morfológica de plural en tales palabras.

Primeramente, se presentarán un par de ejemplos provenientes de los textos bribris publicados en Jara (1993) que muestran que, aunque ocurre en muy pocos casos, la marcación de plural de un referente puede omitirse por completo cuando este número se puede inferir por el contexto. El primer ejemplo se reproduce en (25) (Jara, 1993, p. 51), donde se entiende que kékë 'mayor, antiguo' alude a un referente plural aunque no exista ninguna marcación explícita de este número en la cláusula.

$$
\begin{aligned}
& \text { Eẽ cha kékë i chè ák tso' tã̃̃ ë tchötsã } \\
& \text { allá pues mayor } 3 \text { decir-IMP piedra haber grande-AUM por.todas.partes }{ }^{11} \\
& \text { 'Dicen los antiguos que ahí había enormes piedras, por todas partes' }
\end{aligned}
$$


Lo mismo sucede con ie' en (26) (Jara, 1993, p. 93), cuyo contexto (que no se incluye, por razones de espacio) sugiere que este sustantivo personal hace referencia a más de una persona.

\author{
Mìkã ie' dékã kố aì̃ \\ cuando 3 llegar-PRC-DIRASC lugar allá.arriba \\ 'Cuando llegaron (arriba) a aquel lugar'
}

Ahora bien, lo que resta de esta sección se centrará en el análisis de este fenómeno en enunciados descontextualizados, específicamente en los que incluyen varias palabras pluralizables correferentes en una misma cláusula. Primeramente, servirá de base la oración en (27a), donde el número plural del referente de alákölpa 'mujeres' está marcado simultáneamente mediante tres estrategias: el sufijo - $p a$ en el sustantivo, la reduplicación de la raíz del adjetivo y la forma plural del posicional. Tal estructura es perfectamente gramatical, aunque representa cierto grado de redundancia. También se consideraría gramatical y precisa la construcción en (27b), donde el sustantivo y el posicional aparecen en plural, pero el adjetivo en singular. Lo mismo es el caso de (27c), que también contiene dos palabras pluralizables en plural (el adjetivo y el posicional) y solo una en singular (el sustantivo). La oración en (27d), por su lado, se consideraría agramatical, ya que únicamente el posicional está en plural y las otras dos palabras pluralizables en singular.

(27) a. Alákölpa buàmbuáala tulur kula’ kĩ. mujer-PL bonito-PL sentado.PL banca en 'Las mujeres bonitas están sentadas en una banca.'

b. Alákölpa buáala tulur kula' kĩ. mujer-PL bonito sentado.PL banca en

c. Aláköl buàmbuáala tulur kula’ kĩ. mujer bonito-PL sentado.PL banca en

d.* Aláköl buáala tulur kula’ kĩ.

mujer bonito sentado.PL banca en

Si se incluye un numeral mayor de uno en esta cláusula, se acepta que tanto el adjetivo como el posicional aparezcan en su forma singular, sobre todo si el sustantivo tiene referente humano y lleva el sufijo - $p a$, como en (28). Esto se explica posiblemente por el hecho de que un numeral es la estrategia más precisa de expresar el número nominal, por lo que su presencia hace disminuir, a cierto grado, la importancia de la marcación en los otros elementos pluralizables.
Alákölpa buáala tchër ból kula’ kĩ.
mujer-PL bonito sentado dos-CLHUM banca en
'Dos mujeres bonitas están sentadas en una banca.'

La ausencia de marcación de plural en ciertas palabras pluralizables también puede evocar lecturas más específicas. Por ejemplo, la estructura en (29), donde por un lado, el sustantivo está en plural y, por el otro, el adjetivo y el posicional en singular, se interpretaría de modo que el referente consiste en más de una mujer, pero de las cuales una le llama más la atención al hablante.

(29) Alákölpa buáala tchër kula’ kĩ. mujer-PL bonito sentado banca en 
En una cláusula en la que un sustantivo con referente humano y un posicional son las únicas palabras pluralizables, el sustantivo puede aparecer en plural y el posicional en singular, como en el ejemplo (30). Sin embargo, el informante afirma que en este caso, el referente se entendería como singular en términos occidentales, debido a la forma singular del posicional; el plural del sustantivo, por su lado, se interpretaría como una referencia a los cuatro seres que constituyen al humano (cf. sección 3.3). En cambio, tal lectura nunca se daría si ambas palabras estuvieran en plural. Por consiguiente, parece que el sufijo - $p a$ posee la posibilidad de aludir a los seres interiores, mientras que el posicional, por su función de codificar una postura en el espacio físico, siempre hace referencia al número de cuerpos físicos.

$$
\begin{aligned}
& \text { Alákölpa tchër kula' kĩ. } \\
& \text { mujer-PL sentado banca en } \\
& \text { 'La/una mujer está sentada en la banca.' }
\end{aligned}
$$

Todos los ejemplos hasta ahora en esta sección han incluido un sustantivo con referente humano. En cambio, chichi 'perro' en (31) no admite el morfema -pa. La cláusula (31a) es claramente gramatical porque la marcación de plural del referente nominal está presente en todas las palabras posibles: el adjetivo y el posicional. Contrariamente, (31b) no es aceptable, por incluir solo una de estas palabras en plural y otra en singular. Asimismo, el numeral presente en (31c) permite que el adjetivo vaya en singular, ya que el posicional también codifica el número plural. También (31d) se considera gramatical, por incluir dos elementos que expresan plural (el adjetivo y el numeral) y solo una palabra pluralizable en singular (el posicional).

Finalmente, se presentará un ejemplo de una cláusula en la que solamente un adjetivo y el sufijo verbal -yar pueden especificar el número del referente nominal. En este caso, si el referente es plural, ambas formas deben aparecer en ese número, como en (32a). De lo contrario, con una palabra en singular y otra en plural, como se ejemplifica en (32b), la oración no se considera gramatical.
a. Chichi tsírtsir póneyar. perro pequeño-PL irse-PRM-PL 'Los perros pequeños se fueron.'
*Chichi tsìr póneyar. perro pequeño irse-PRM-PL

En resumen, cuando un conjunto de palabras pluralizables aluden a un mismo referente plural, el bribri parece requerir que la mayoría de estas aparezca en su forma plural. 
En estos casos, los adjetivos parecen ser los más propicios a no adquirir tal forma. Los patrones observados no constituyen restricciones sintácticas de concordancia, sino requisitos lógicos para evitar la confusión o ambigüedad en cuanto al número del referente.

\section{Conclusiones}

En este artículo se presentaron las diferentes estrategias empleadas en el bribri para indicar el número nominal, el cual se codifica gramaticalmente como singular o plural. Además, se apreció cómo la Jerarquía de Empatía Universal se manifiesta en la gramática, por medio de las restricciones que determinan cuáles palabras pueden recibir cada tipo de marcación: los sustantivos personales referidos a la primera y la segunda persona presentan raíces propias de plural (en la mayoría de los casos, más bien de asociación), los sustantivos con referente humano de la tercera persona admiten el sufijo - pa (o una reduplicación en el caso de alà 'niño'), mientras que los otros tipos de marcación de plural se dan con cualquier tipo de referente. Por lo tanto, las categorías de la Jerarquía de Empatía relevantes para la expresión del número nominal en bribri son las que se exponen en (33).

$$
1^{\mathrm{a}} / 2^{\mathrm{a}} \text { persona }>\text { humano }>\text { no humano }
$$

En lo que concierne a la obligatoriedad de la marcación de plural, se observó que no existe una regla fija de concordancia en bribri. Más bien, el sistema es regido por el motivo de evitar ambigüedad en cuanto al número. De esta manera, tanto el contexto discursivo como la marcación de plural en otros elementos de la cláusula pueden permitir que algunas palabras pluralizables aparezcan en singular. Además, este fenómeno posibilita la expresión de ciertos matices que difícilmente se pueden dar en lenguas de concordancia de número obligatoria.

Cabe enfatizar que queda mucho por analizar en cuanto a la expresión del número nominal en el discurso, sobre todo para dar cuenta de los factores que impulsen la omisión de toda marcación explícita de plural de un referente en una cláusula.

\section{Abreviaturas}

$\begin{array}{ll}* & \text { El ejemplo es agramatical } \\ - & \text { Linde de morfema } \\ . & \text { Separa significados o elementos que en conjunto traducen un solo elemento } \\ \text { 1SG } & \text { Sustantivo personal de primera persona del singular } \\ 1 \mathrm{PE} & \text { Sustantivo personal de primera persona del plural exclusiva } \\ 3 & \text { Sustantivo personal de tercera persona } \\ \text { AG } & \text { Posposición que marca el agente semántico } \\ \text { AUM } & \text { Aumentativo } \\ \text { AUX } & \text { Verbo auxiliar } \\ \text { CLALA } & \text { Clasificador ALARGADO } \\ \text { CLHUM } & \text { Clasificador HUMANO } \\ \text { CLPAQ } & \text { Clasificador PAQUETE } \\ \text { CLRBA } & \text { Clasificador RACIMO DE BANANO } \\ \text { CLRED } & \text { Clasificador REDONDO }\end{array}$




$\begin{array}{ll}\text { COP } & \text { Cópula } \\ \text { DIRASC } & \text { Direccional de movimiento ascendente } \\ \text { DIRPEN } & \text { Direccional de movimiento de penetración } \\ \text { DIRSEP } & \text { Direccional de separación } \\ \text { ERG } & \text { Posposición que marca el ergativo } \\ \text { IMP } & \text { Imperfectivo } \\ \text { INF } & \text { Infinitivo } \\ \text { PL } & \text { Plural } \\ \text { PRC } & \text { Aspecto perfectivo reciente } \\ \text { PRM } & \text { Aspecto perfectivo remoto }\end{array}$

\section{Notas}

1. El término número nominal es utilizado, entre otros, por Lucy (1996, p. 23). Este concepto se distingue del número verbal, noción empleada por algunos autores con referencia al número de eventos o estados denotados por un verbo.

2. La gran mayoría de los hablantes del bribri habita en Costa Rica; en el Censo Nacional de Población y Vivienda 2011 de Costa Rica, alrededor de 7000 personas se declararon hablantes del bribri. Además, el Censo Nacional de Población y Vivienda 2010 de Panamá muestra que unos 1000 habitantes de ese país se consideran parte del pueblo bribri, pero el reporte no incluye el número de hablantes de la lengua.

3. Los tres grupos dialectales principales del bribri son denominados por la comunidad más importante de su área, todas en Costa Rica: Coroma y Amubre del lado atlántico de la Cordillera de Talamanca, y Salitre del lado pacífico (Jara y García, 2013, p. 2).

4. Se emplea el término sustantivo personal en lugar del tradicional pronombre personal, dado que estas palabras no siempre funcionan como "sustitutos" de un sustantivo o un sintagma nominal, especialmente no en el caso de las que aluden a la primera y la segunda persona.

5. En este artículo se hace uso de la ortografía bribri empleada por Jara y García (2013); este es el caso también en los ejemplos provenientes de fuentes que emplean una ortografía diferente.

6. $\quad$ Es posible que el inventario de clasificadores varíe según el dialecto.

7. Cabe resaltar que, en la ortografía utilizada en este artículo, a diferencia del Alfabeto Fonético Internacional, el acento grave representa tono alto y el acento agudo, tono descendente.

8. En la literatura existente sobre el bribri, estas palabras reciben dos denominaciones distintas: "posicionales" en Constenla, Elizondo y Pereira (1998) y "auxiliares de tso"” en Jara y García (2009, 2013). En el presente artículo son tratados bajo el primer término, principalmente porque el término "auxiliares" podría provocar que se confundan con los verbos auxiliares. Además, su semántica y sus funciones son similares a una categoría de palabras en las lenguas mayas que también se denomina "posicionales".

9. Contrario a lo expuesto en Constenla, Elizondo y Pereira (1998, p. 53), donde se afirma que este sufijo se añade únicamente a las posposiciones y los verbos intransitivos.

10. El aspecto perfectivo presenta dos formas: reciente y remoto. El reciente se utiliza para aludir a eventos llevados a cabo anteriormente el mismo día (que para los bribris inicia y termina al anochecer alrededor de las seis de la tarde). El perfectivo, por su parte, se emplea para eventos realizados antes del día actual. Estos términos corresponden a los que se utilizan en Jara y García (2009; 2013); en Constenla, Elizondo y Pereira (1998) son denominados "perfecto prospectivo" y "perfecto improspectivo", respectivamente.

11. Las glosas en los ejemplos tomados de Jara (1993) difieren de las que son presentadas por esta autora, con las finalidades de ilustrar mejor los fenómenos relevantes para el presente artículo y asegurar la uniformidad con las glosas en los demás ejemplos. 


\section{Bibliografía}

Censo Nacional de Costa Rica. (2011). X Censo Nacional de Población y VI de Vivienda 2011. http://www.inec.go.cr. [Consulta 10 de mayo de 2015].

Censo Nacional de Panamá. (2010). Censos Nacionales 2010: XI de Población y VII de Vivienda. http://contraloria.gob.pa/inec. [Consulta 10 de mayo de 2015].

Constenla-Umaña, A., Elizondo-Figueroa, F. y Pereira-Mora, F. (1998). Curso básico de bribri. San José: Editorial de la Universidad de Costa Rica.

Corbett, G. G. (2000). Number. Cambridge: Cambridge University Press.

Greenberg, J. H. (1963). Some universals of grammar with particular reference to the order of meaningful elements. Universals of human language. (73-113). Londres: MIT Press.

Grinevald, C. (2006). The expression of static location in a typological perspective. Por M. Hickmann y S. Robert (Comps.). Space in languages: Linguistic systems and cognitive categories. (29-58). Ámsterdam/Filadelfia: John Benjamins.

Jara-Murillo, C. V. (1993). I ttè. Historias bribris. San José: Editorial de la Universidad de Costa Rica.

Jara-Murillo, C. V. (2013). Morfología verbal de la lengua bribri. Estudios de Lingüistica Chibcha. 32, 95-152.

Jara-Murillo, C. V. y García-Segura, A. (2009). Se’ é yawö bribri wa. Aprendemos la lengua bribri. San José: Universidad de Costa Rica y UNICEF.

Jara-Murillo, C. V. y García-Segura, A. (2013). Se’ ttö bribri ie. Hablemos en bribri. San José: E-Digital.

Kibort, A. y Corbett, G. G. (2008). Number. Grammatical Features. http://www.features. surrey.ac.uk/features/number.html. [Consulta 10 de mayo de 2015].

Krohn, H. S. (2014). Semántica de los clasificadores numerales en el bribri de Coroma. Estudios de Lingüística Chibcha. 33, 209-239.

Langacker, R. W. (1991). Foundations of Cognitive Grammar, Vol. 2: Descriptive Application. Stanford: Stanford University Press.

Lucy, J. A. (1996). Grammatical categories and cognition. A case study of the linguistic relativity hypothesis. Cambridge: Cambridge University Press.

Smith-Stark, T. C. (1974). The plurality split. Chicago Linguistic Society. 10, 657-671. 